\title{
LITERATURA DE MASSA E MERCADO
}

\author{
Gláucio Aranha ${ }^{1}$ \\ Fernanda Batista $^{2}$
}

\begin{abstract}
Resumo: Partindo da percepção da Literatura de Massa como um modelo de produção literária intrinsecamente ligado à sociedade de consumo contemporânea, propõem-se uma reflexão acerca de seus elementos paradigmáticos na busca da representação sócio-cultural deste objeto. $O$ ensaio privilegia um olhar fronteiriço entre os campos da literatura e da comunicação social, evidenciando os elementos que contribuíram para a consolidação deste modelo literário no trajeto entre as primeiras publicações em jornais (folhetim) até a consolidação do formato best seller. Destaca-se, ainda, como o mercado impactou sobre a esfera valorativa da obra literária, passando a disputar o espaço de legitimação anteriormente restrito à instituição literária e a seus agentes.
\end{abstract}

Palavras-Chave: Literatura de massa. Estudos de mídia. Literatura comparada.

\begin{abstract}
On the perception of mass literature as literary production intrinsically linked to the contemporary consumption society, it is proposed here a reflection about its paradigmatic elements in the pursuit of sociocultural representations. Looking for the fields between literature and social media, the approach used in this work emphasizes the elements that contributed to the consolidation of this literary model. It was also pointed out how the market influences the value of literary work, a space previously restrict to the literary institution and their agents.
\end{abstract}

Key-words: Mass literature. Media studies. Comparative literature.

\section{Introdução}

O surgimento do romance-folhetim marcou o início de um novo modelo de expressão literária caracterizado pela simplificação formal e acessibilidade da linguagem, dentre outros aspectos. Nestas histórias, verifica-se a predominância de personagens comuns e da estrutura narrativa do herói clássico. Tal modelo se consolidou no mercado, impulsionado,

\footnotetext{
${ }^{1}$ Doutor em Letras (Literatura Comparada), pela Universidade Federal Fluminense; mestre em Comunicação, Imagem e Informação, pela Universidade federal Fluminense (UFF) e graduado em Direito pela Universidade Federal de Juiz de Fora (UFJF). Atua como pesquisador associado do Instituto de Ciências Cognitivas (ICC). Tem experiência em literatura comparada, estudos comparados de mídias e cultura pop contemporânea. E-mail: glaucioaranha@gmail.com e aranha@cienciasecognicao.org .

${ }^{2}$ Graduada em Comunicação Social (Publicidade e Propaganda) pela Universidade Federal Fluminense (UFF).
} 
principalmente, pelas transformações econômicas e sociais da revolução industrial. A urbanização e a alfabetização em massa permitiram que uma imensa camada da sociedade estivesse apta à leitura, expandindo o universo de leitores e a oferta de textos. Este momento é assumido Eliana Paz (2004) como um marco na "democratização" de um modelo cultural. O livro, até então destinado a uma "casta superior” de consumidores, foi transformado em bem cultural de largo consumo, um produto de massa.

O objetivo deste ensaio é refletir sobre as características e paradigmas do que se convencionou chamar de Literatura de Massa ao longo do tempo, entendendo tais referenciais como base para a consolidação de um importante aspecto da indústria editorial contemporânea. São, assim, pontuados os principais aspectos de sua gramática estilística, com o intuito de avaliar a adaptação do fazer literário às demandas da sociedade de consumo, instaurando um novo público e um novo modelo textual.

Por ser um produto dirigido às massas, de grande penetração, esta literatura sofre influência direta dos fatores de mercado, tendo sido estimulada pelo incremento da capacidade de reprodução e distribuição dos bens culturais. Deste modo, pensar a lógica imanente a esta forma importa pensar a lógica comunicacional da mesma (reprodução/distribuição) como elemento relevante no processo de consolidação deste bem cultural. No mesmo sentido que Nízia Villaça, entendemos que

(...) os Estudos Literários tornam-se um ramo dos Estudos da Mídia e dos Estudos Culturais, no intento de verificar como estes meios têm apelado para a reorganização do mercado de bens simbólicos de um lado, e de outro, para o reposicionamento de hierarquias na prática cultural. (Villaça, 2002: 55).

A reflexão proposta permitirá a melhor compreensão e análise crítica desta literatura de entretenimento em uma sociedade marcada pelo avanço tecnológico e pela consolidação do consumo como critério de validação artística.

\section{Revolução Industrial e Literatura}

A Revolução Industrial trouxe complexos desdobramentos econômicos, culturais, políticos e, principalmente, sociais, marcando o início da modernidade (Harvey, 2004; Nicolacida-Costa, 2002). Sob a pressão da Revolução Industrial, os rápidos acontecimentos da Idade Moderna levaram a uma mudança na perspectiva da sociedade em relação à cultura letrada, tornando-se esta um "serviço público coletivo". Como bem destaca Benjamin (1981), a obra de arte toma uma proporção coletiva não apenas por se dirigir a uma massa, mas também por ser custeada por esta, pela coletividade de consumidores. 
Assim, a comunidade de leitores-consumidores passa a desempenhar um importante papel de legitimação. Os índices de venda (“campeões de venda”, “os mais vendidos”) tomam a forma de indicadores de qualidade e excelência para o grande público. Portanto, o fato de ser mais vendido agrega valor ao bem ofertado. Marisa Lajolo e Regina Zilberman (2001) comprovam que a influência do mercado sobre o valor de uma obra literária não é propriamente uma novidade, entretanto com a ampliação do mercado para massas consumidoras, temos uma transferência desta influência do mecenato para o respaldo popular. De onde temos, por exemplo, a relevância editorial das tarjetas indicando que este ou aquele livro tiveram um determinado número de vendas (“mais de 1 milhão de cópias vendidas”).

A cultura letrada passou a lidar com novos critérios e elementos, tais como a emergência do indivíduo-massa, que Alfredo Bosi descreve como:

a personalidade construída a partir da generalização da mercadoria, quando entra no universo da escrita (o que é um fenômeno deste século), o faz com vistas ao destinatário, que é o leitor-massa, faminto de uma literatura que seja especular e espetacular. Autor e leitor perseguem a representação do show da vida, incrementado e amplificado. Autor-massa e leitor-massa buscam a projeção direta do prazer e do terror, do paraíso do consumo ou do inferno do crime - uma literatura transparente, no limite, sem mediações, uma literatura de efeitos imediatos e especiais, que se equipara ao cinema documentário, ao jornal televisivo, à reportagem ao vivo. (Bosi, 2002: 249)

As constantes transformações tecnológicas alteraram profundamente as condições de vida do trabalhador braçal, exigindo uma maior especialização da mão-de-obra que, até então, era predominantemente composta por indivíduos não alfabetizados. Martyn Lyons e Cyana Leahy (1999) destacam que a intensa migração para as cidades em busca de um novo tipo de trabalho, mais qualificado, e a exigência de novos conhecimentos científicos, inexistentes em um período anterior, auxiliaram na consolidação do livro como referencial simbólico para erudição e conhecimento. Em tese, o sujeito-leitor seria detentor de maior saber que seus pares pela sua condição de consumidor de livros. Tal representação deu espaço para a formação de um novo nicho consumidor da cultura letrada: a classe trabalhadora.

Paralelamente a essa nova demanda, os avanços tecnológicos permitiram, cada vez mais, a difusão da produção de materiais impressos pelo barateamento do custo. Assim, um universo maior de pessoas teve acesso aos livros que, anteriormente, podiam ser considerados artigos de luxo. O surgimento destes novos decifradores do código impresso deu origem a um novo nicho de consumo de textos. Como expõe Vanilda Paiva e colaboradores (1998), este fato contribuiu também para o crescimento do nível de escolarização da classe popular e o alargamento das fronteiras da literatura. 
Na primeira metade do século XIX, surgiram em Paris os romances-folhetins (Meyer, 2002; Diniz et alli, 2003). Inicialmente, este formato ganhou o espaço de uma parte do jornal no qual eram publicadas críticas literárias, receitas culinárias e outras variedades, compondo assim, um “rodapé” do jornal. Em julho de 1836, Émile de Girardin, editor do jornal francês La Presse, começou a publicar trechos adaptados de romances, que já haviam sido publicados do formato de livros. Em cada nova edição do jornal havia um gancho, o qual seria complementado por um novo trecho na edição posterior. A farta aceitação da proposta promoveu a elevação nos índices de vendas dos jornais contribuindo para o barateamento das publicações. Isabel Pires (2006) destaca como o novo modelo de romance agradou ao numeroso operariado francês, obrigando os jornais a publicá-lo de maneira permanente, na disputa acirrada por leitores. Tal fato vai ao encontro da percepção de Aníbal Ford sobre o surgimento das expressões culturais midiatizadas:

a cultura dos meios de comunicação "populares e baratos", nasce, em grande medida, marcada e calcada nas tradições, nos gêneros, nos saberes e nas necessidades cognitivas existentes nas classes populares (um conjunto que, obviamente, tem seus correlatos em formações culturais não populares mas tampouco hegemônicas). (Ford, 1999: 197)

A orientação editorial destes conteúdos focava o operariado, enquanto consumidor de ficção escrita, privilegiando características estruturais e estilísticas que atendiam a esta demanda, tais como: o uso de linguagem cotidiana, arranjos gramaticais simplificados, períodos curtos, minimização dos recursos estilísticos e focalização em enredos que correspondessem à experiência de vida de seus leitores ou às representações já estabelecidas em seu imaginário. É possível notar neste processo que os paradigmas estilísticos do próprio canal (jornal) penetravam, entranhavam e estabeleciam a orientação formal das narrativas por ele veiculadas. Com o bom resultado destas propostas editoriais as histórias publicadas, que antes eram apenas adaptadas para este novo formato, passam a ser escritas especificamente para o formato folhetim. Marlyse Meyer (1996) aponta como mais tarde estas mesmas histórias foram condensadas e transformadas em "livro" para publicação, devido à grande demanda do público, como, por exemplo, as obras de Alexandre Dumas.

O folhetim se tornou, então, uma das principais formas de entretenimento textual das camadas populares na época da Revolução Industrial. Velozmente, este modelo penetrou e marcou toda a produção literária voltada para o consumo em massa, revelando-se um dos maiores motores da indústria editorial contemporânea. Como destaca Eliana Paz (2004), as listas de mais vendidos nas últimas décadas arrolam numerosos títulos oriundos da literatura de entretenimento, sendo ínfima a (eventual) presença de um clássico entre aquelas listas. 


\section{A gramática dos Best-Sellers}

A leitura de uma obra da literatura de massa é, muitas vezes, vista como “inferior” por parte de teóricos mais tradicionalistas, especialmente na crítica literária. Posicionamento este muitas vezes adotado em relação a outras expressões literárias de cunho popular, sobre os quais pesa a acusação frequente de "nada exigir" do leitor, além do mero entretenimento e desfrute, em contraposição à chamada alta literatura ou literatura culta. Este paradigma, entretanto, foi sagazmente revisto por Umberto Eco (2000), ao afastar as expressões literatura de massa, baixa literatura, paraliteratura em favor de uma distinção entre literatura de entretenimento e literatura de proposta. Estas categorias seriam regidas, a priori, por dois critérios diferenciais, quais sejam: originalidade e esforço.

Quanto à originalidade, Eco identifica na literatura de entretenimento a prevalência de uma forma que se despoja da pretensão de exploração de caminhos demasiadamente originais em favor de uma preocupação com a abrangência da penetração, com a aproximação em relação ao leitor. Com isto, verifica-se a maior aproximação de um "gosto médio", um ponto intermediário entre o inovador e o senso comum. Por outro lado, a literatura de proposta investiria justamente na busca do singular, da experiência diferenciada de expressividade e leitura.

No tocante ao critério esforço, tem-se na literatura de entretenimento uma tendência à redução do esforço do leitor, valendo-se de uma linguagem mais cotidiana, mais corrente. Isto não significa que nesta modalidade esteja presente certo desleixo ou descaso com o leitor, mas sim uma economia em relação ao universo vocabular e aos recursos gramaticais que possam dificultar a leitura de um amplo naipe de leitores. Vale destacar aqui não se tratar de aspectos valorativos, mas formais. Esta preocupação com a acessibilidade do texto está ausente na literatura de proposta, que pode investir até mesmo em dinâmicas "pouco digeríveis”, em favor de um desafio ao leitor. Algumas vezes, esta abertura pode comprometer a fruição da leitura em relação ao "leitor médio", exigindo, por exemplo, conhecimentos anteriores que viabilizem a melhor percepção dos intertextos, além de um vocabulário mais rico e maior acuidade cognitiva. Este tipo de disposição vai contra as estratégias da escritura para a coletividade.

Na literatura de entretenimento é possível notar o empenho autoral no sentido de promover uma experiência de totalidade em relação do leitor, ou seja, uma experiência de leitura que aposta na vinculação e aproximação da relação texto-leitor. Para tanto, a poética deste modelo investe no resgate de elementos clássicos (tensão, clímax, desfecho, catarse). Tais elementos são rearticulados com uma estrutura que, via de regra, lança mão dos "ganchos", objetivando manter a tensão durante o máximo de tempo possível, adiando o clímax. Os ganchos são uma clara herança do modelo folhetinesco, que permeia grande parte de outras 
formas derivadas de literatura de entretenimento (romances policiais, histórias em quadrinhos, dentre outras).

Além desta característica diferencial, é possível perceber ainda outras ao se comparar a literatura de entretenimento com a literatura de proposta. Muniz Sodré (1997) entende que haveria dois tipos de literatura, cada uma dotada de especificidades no tocante à produção e ao consumo, sendo por ele denominadas de literatura "culta" e "de massa". Esta seria a manifestação de um discurso específico e não uma forma menor. Sodré se afasta da percepção de que haveria uma "rivalidade" entre estas formas, bem como dos discursos que acusam a literatura de entretenimento, no sentido de ser ela uma mera utilização menor e vulgar do discurso literário. Pelo contrário, entende que esta categoria atende a um público que, anteriormente, não era consumidor de literatura e que necessitava de um produto com características específicas para ele. Neste sentido, aproxima-se da Teoria do Degrau, de José Paulo Paes (2000), ao entender que:

(...) uma leitura média de entretenimento, estimuladora do gosto e do hábito da leitura, adquire o sentido de degrau de acesso a um patamar mais alto onde o entretenimento não se esgota em si mas traz consigo um alargamento da percepção e um aprofundamento da compreensão das coisas do mundo. (Paes, 2000: 28)

Assim, a literatura de massa vem "democratizar” esta cultura literária anteriormente restrita a certos segmentos da sociedade, adaptando-a para uma nova realidade. Para tanto, utiliza-se de aspectos estruturais e estéticos específicos.

O folhetim, antecessor do best-seller, instaurou um modelo de narrativa fracionado, constituindo-se em uma corrente cujos elos eram acrescentados a cada volume do jornal em que eram publicados, edificando-se lentamente perante o leitor. Pires (2002) entende que tal fato contribuiu, significativamente, para o próprio processo de consolidação deste modelo, historicamente aliado às condições do contexto, ou seja, em concordância com as condições do público ao qual se propunha atingir. Posteriormente, com o largo consumo do folhetim, ocorreu a "desfragmentação" dessa narrativa, quando o folhetim/romance tomou a forma do romance/folhetim, passando a ser publicado como histórias condensadas em formato de livros (Meyer, 2000). Semeou-se, assim, a base para o que mais tarde culminou no conceito mais corrente de best-seller, qual seja: uma obra literária extremamente popular cujo valor seria colegitimado pelo próprio mercado, ganhando evidência e aval através da inclusão na lista dos "mais vendidos".

\footnotetext{
${ }^{3}$ Cumpre observar que do ponto de vista terminológico esta divisão parece menos clara e precisa do que a proposta por Eco e exposta anteriormente, a qual adotamos.
} 
Embora o aspecto da fragmentação da narrativa, aparentemente, tenha sido suprimido pelo volume único, é possível observar ainda a ordenação de capítulos curtos como uma característica marcante de muitos destes livros, bem como a presença dos ganchos entre os capítulos, remetendo o best-seller ao modelo do romance-folhetim.

Outro elemento marcante é o curso linear da ação nos fatos narrados, formando uma sequência lógica aristotélica, de início, meio e fim, na qual se desenrolam os fatos da história. Este aspecto é determinante para a maior facilidade de adaptações das obras de entretenimento para outros suportes, tais como o cinema, tendo em vista que o investimento primordial dos best sellers está no enredo, em desfavor da exploração da originalidade e do esforço no uso da linguagem, como se dá na literatura de proposta.

Merece destaque, ainda, a forte presença do dialogismo no correr destas narrativas, elemento este que contribui para uma adesão mais intensa do leitor. Aliada a esta estrutura, encontra-se a linguagem simples e leve, objetivando transmitir informações de fácil interpretação popular, minimizando o esforço do leitor, no sentido de não lhe exigir erudição como pré-requisito para a fruição do texto. O que reforça o entendimento de que o principal foco deste gênero está na estruturação do enredo e não na exploração da linguagem.

No tocante à apresentação dos personagens, é possível perceber o desenvolvimento de características como a presença de um herói clássico, recontextualizado e marcado pelo modelo burguês com o qual o grande público facilmente se identifica, por exemplo, em romances sentimentais cujo conflito repousa na distinção entre classes sociais, em romances policiais onde o pensamento racional e cientificista se apresenta como revelador da verdade, dentre outros. Ainda neste sentido temos a prevalência do modelo da tradição proppiana de estruturação narrativa (Propp, 1984). Alguns conflitos muito comuns são ainda: o maniqueísmo na luta do bem contra o mal, o combate ao monstruoso, a superioridade da nobreza de caráter do herói etc.

Outra marca está no "final feliz" - o famoso happy end - característico dos best-sellers. Como destaca Alfredo Bosi (1983), todos os elementos que, permeados por boa dosagem de realismo e conservadorismo, vão concorrer para a instauração da crise serão reestruturados no final com o restabelecimento da ordem.

\section{Literatura de Entretenimento e Mercado}

Enquanto a literatura de proposta tem, a priori, como agentes de legitimação a crítica e o âmbito acadêmico, a literatura de entretenimento tem no mercado o principal agente valorativo desta produção. Assim, estar entre “os mais vendidos” significa não apenas um resultado, mas uma agregação de valor e consolidação da qualidade de uma obra para a massa, legitimada pela própria massa através do consumo. Vale lembrar que como se trata de uma 
produção cultural de larga escala, a necessidade principal é agradar ao público com o fim de alimentar a indústria.

Nesta busca, verifica-se a exploração da adequação temática a determinado contexto sócio-histórico, como, por exemplo, o "surgimento" no mercado de autores do Oriente Médio após a Guerra do Iraque nas livrarias ocidentais, tais como Khaled Hosseini, Marjane Satrapi e outros. A produção em massa de literatura não pode, por conseguinte, ser dissociada da lógica da indústria cultural e da capacidade desta de multiplicação das variantes narrativas, por exemplo, a narrativa da série Harry Potter migrando para o cinema, jogos eletrônicos e outros. O resultado das vendagens funciona como força propulsora para tais migrações. No caso de Harry Potter, Chris Crowe (2001) observa como as elevadas vendas estenderam as fronteiras da obra para além do gênero infanto-juvenil, que em tese definiria seu consumidor primário. A migração da narrativa para o cinema, por sua vez, alargou ainda mais o público, passando a influir na própria narrativa impressa, por exemplo, os personagens passaram a ter características dos atores. A resposta do mercado agregou assim valor, enquanto literatura de entretenimento, despertando nos agentes do mercado maior interesse (Whited, 2003; Anatol, 2003).

This success is a triumph of marketing. Perhaps not marketing in its most traditional or conventional form, but marketing as it has been developing and will continue to develop. Harry Potter - or his creator, JK Rowling, and the marketing machine that now surrounds her creation - has used the techniques of branding and marketing in a way that can only be envied (and will no doubt be copied) by other superbrands. (Observer, 2005) ${ }^{4}$

Harry Potter é um valioso exemplo do modo como se estabelece a relação valorativa na literatura de entretenimento, ao mesmo tempo evocando para si as duas referências levantadas por Eco sobre os livros de sucesso, qual seja: "Um livro obtém sucesso somente em dois casos: se dá ao público o que ele espera ou se cria um público que decide esperar o que o livro lhe dá.” (Eco, 1989: 104). Ao mesmo tempo em que trabalha com a releitura de estruturas tradicionais, já consolidadas no imaginário popular, dando ao público "o que ele espera” cria, por meio do resgate da matriz folhetinesca e dos ganchos entre os volumes "um público que decide esperar o que o livro lhe dá”. Sendo importante destacar, neste caso, que ambos os elementos se retroalimentam, já que o que o livro tem a dar a este público que espera é exatamente o que ele já quer. Vale aqui, nas palavras de Eliana Paz, lembrar que:

\footnotetext{
4 "Este sucesso é um triunfo do marketing. Talvez não do marketing em sua mais tradicional ou convencional forma, mas do marketing assim como vem sendo e continuará sendo desenvolvido. Harry Potter - ou seu criador, JK Rowling, e a máquina de marketing que agora envolve a sua criação - usou de técnicas de 'branding' e marketing de uma maneira que só pode ser desejada (e sem dúvida será copiada) por outras super-marcas."
} 
Se o best seller é resultado do processo de industrialização e efeito da ação capitalista sobre a cultura, é preciso levar em conta também que esse tipo de narrativa tende a constituir-se em "campeão de vendas" porque se configura uma poderosa estimuladora de leitura, isto é, tem o poder de mobilizar o olhar e estimular a imaginação do leitorconsumidor. O fascínio duradouro desta literatura indica que não se pode analisá-la com uma visão simplista e redutora, limitando-a ao campo de efeito de estratagemas mercadológicos ou como subproduto da literatura culta. (Paz, 2004: 2)

\section{Conclusão}

A chamada literatura de massa surgiu em uma época de grandes transformações econômicas e sociais, voltada para um público que até então não possuía acesso fácil a nenhum tipo de cultura letrada. Esta grande massa foi a principal responsável pelo seu sucesso, através do consumo de obras mais acessíveis que levavam entretenimento a uma camada até então excluída (classe trabalhadora).

Foi através da expansão deste consumo que a literatura de massa passou de sua forma mais simples, como rodapés de jornais impressos, para formas mais elaboradas, como os primeiros livros que traziam as histórias de maior sucesso condensadas. Este processo não se esgotou, continuando tal modelo a se adaptar aos hábitos de consumo de uma sociedade em constante mutação, transformando-se sem perder suas características primordiais e ganhando contornos singulares através de novas mídias, convergindo e inovando. Em uma sociedade marcada pela imbricação dos meios de comunicação de massa e as manifestações culturais, estabelecer um olhar atento às suas singularidades e metamorfoses é uma exigência acadêmica permanente que precisa ser observada e relida com regularidade.

\section{Referências bibliográficas}

ANATOL, G.L. (ed.). Reading Harry Potter: Critical Essays. Westport, CT: Praeger, 2003.

BENJAMIN, W. (1981). A obra de arte na época de suas técnicas de reprodução. Coleção Os Pensadores [Benjamin, Adorno, Marcuse, Horkheimer]. São Paulo: Abril Cultural.

BOSI, A. História Concisa da Literatura Brasileira. São Paulo, Cultrix, 1983.

BOSI, A. Literatura e resistência. São Paulo: Cia das Letras, 2002. 
CROWE, C. 'Young Adult Literature: The Problem with YA Literature'. The English Journal, Vol. 90, No. 3, The Lure of Young Adult Literature (Jan., 2001), pp. 146-150. DINIZ, P.S.; LIMA, A.X.; FARIA, R.M. da R.; FERREIRA, N.N. Construção do Público leitor e investigação lingüística em romances-folhetins em jornais do século $X I X$. In: XII Congresso ASSEL-RIO - Linguagens: modos de dizer, modos de fazer, 2003. Rio de Janeiro, 2003.

ECO, U. Sobre os espelhos e outros ensaios. Rio de Janeiro: Nova Fronteira, 1989.

ECO, U. Apocalípticos e integrados. Série Debates 19. São Paulo: Perspectiva, 2000.

FORD, A. Navegações: comunicação, cultura e crise. Rio de Janeiro: Ed. UFRJ, 1999.

HARVEY, D. Condição pós-moderna. São Paulo: Edições Loyola, 2004 (original de 1989).

LAJOLO, M. e ZILBERMAN, R. O preço da leitura: leis e números por detrás das letras. Série Temas, V. 76. São Paulo: Ática, 2001.

LYONS, M. \& LEAHY, C. A palavra impressa: história da leitura no século XIX. Rio de Janeiro: Casa da Palavra, 1999.

MEYER, M. Folhetim. São Paulo: Cia. Das Letras, 1996.

MEYER, M. Um fenômeno de leitura, o romance-folhetim francês do século XIX (roman-feuilleton) e sua repercussão no Brasil. In: A mídia impressa, o livro e as novas tecnologias. Org. PERUZZO, C.M.K. e ALMEIDA, F.F. de. São Paulo, Campo Grande: Intercom UNIDERP, 2002. p. 137-153 Coleção Intercom de Comunicação, v. 15. $85-87392-24-7$

NICOLACI-DA-COSTA, A.M. Technological revolutions and subjective transformations. Psic.: Teor. e Pesq. , Brasília, v. 18, n. 2, 2002 . Disponível em: $<$ http://www.scielo.br/scielo.php?script=sci_arttext\&pid=S0102-

37722002000200009\&lng=en\&nrm=iso $>$. Acesso em: 26 Apr 2008. doi: 10.1590/S0102-37722002000200009

OBSERVER. Harry Potter, marketing magician. Observer, Domingo, 26 jun 2005.

Disponível

em

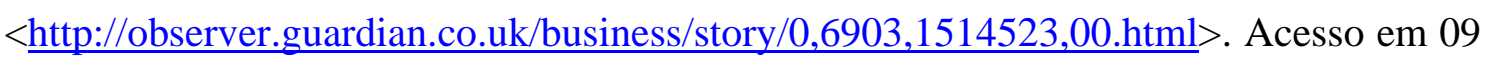
jul 2007, 16:44. 
PAIVA, V.; GUIMARÃES, E.; PAIVA, E.; e DURÃO, A. Revolução educacional e contradições da massificação do ensino. In: Contemporaneidade e educação, Ano III, $1^{\circ}$. Semestre, 1998.

PAZ, E. H. Massa de Qualidade. In: I Seminário Brasileiro sobre o Livro e História Editorial, 2004, Casa de Rui Barbosa. Rio de Janeiro: Casa de Rui Barbosa. Disponível em www.livroehistoriaeditorial.pro.br/pdf/elianehpaz.pdf, Acesso em 09/01/07.

PIRES, I. Literatura e comunicação de massa no Brasil. Dissertação de mestrado em literatura brasileira, UERJ, nov. 2002.

PROPP, V. Morfologia do conto maravilhoso. Rio de Janeiro: Forense Universitária, 1984.

SODRÉ, M. Best Seller: A Literatura de Mercado. Série Princípios. São Paulo: Ática, 1997.

VILLAÇA, N. Impresso ou eletrônico? Um trajeto de leitura. Rio de Janeiro: Mauad, 2002.

WHITED, L. McGonagall's Prophecy Fulfilled: The Harry Potter Critical Library. The Lion and the Unicorn, Volume 27, Number 3, September 2003, pp. 416-425. 